\title{
Effects of process parameters on the mechanical properties and morphology of stitched and non-stitched carbon/epoxy liquid resin-infused NCF laminate, out of autoclave and out of oven
}

\author{
Alvine Njionhou • Florentin Berthet • Bruno Castanié
}

\begin{abstract}
The effects of resin infusion process parameters on the mechanical properties of stitched or non-stitched composite laminates out of autoclave were studied using the design of experiment method. This method was chosen due to the complexity of the problem. The preforms used were laminates of multi-axial quasi-isotropic non-crimp fabric (NCF), either stitched or non-stitched. A literature review identified nine parameters as the key design-of-experiment factors: sewing; the number of NCFs; the number of highporous media; the interaction between the number of NCFs and the number of high-porous media; the mould temperature, injection temperature and cure temperature; the position of the preform; and, finally, the vacuum level. The mechanical properties studied and the morphological analysis carried out concerned the resistance in tension, compression and shear, the glass transition temperature, the thickness of the finished laminate, and the fibre volume fraction and porosity. The study revealed the best suited manufacturing conditions.
\end{abstract}

\footnotetext{
A. Njionhou $\cdot$ F. Berthet $(\bowtie)$

Université de Toulouse, Mines d'Albi, INSA, UPS, ISAE ICA

(Institut Clément Ader),

Ecole des Mines d'Albi (EMAC), Campus Jarlard,

Albi cedex 09 81013, France

e-mail: florentin.berthet@enstimac.fr

B. Castanié

Université de Toulouse, INSA, Mines d'Albi, UPS, ISAE, ICA

(Institut Clément Ader),

135 Avenue de Rangueil,

Toulouse Cedex 31077, France

e-mail: bruno.castanie@insa-toulouse.fr
}

Keywords Resin transfer moulding (RTM) · Carbon fibres · Mechanical properties · Porosity · Voids $\cdot$ Liquid resin infusion $\cdot$ Probabilistic method

\section{Introduction}

When developing composite structures for the aerospace industry, the question of economic competitiveness needs to be taken into account. For this reason, special attention is being paid today to out-of-autoclave processes. While many technologies may prove viable $[1,2]$, liquid resin infusion (LRI) was selected for this study. LRI seems to be one of the most promising technologies because it is easy to use. The process makes it possible to obtain composites of good quality [1] for the aeronautics field, through the use of stitching.

Understanding the link between manufacturing and mechanical properties (Fig. 1) is technologically interesting, in that it should enable improvements to be made in process control and help in establishing if parts manufactured under different process conditions are viable. However, the degree of dependence of the mechanical properties of composites on the process conditions is still only partially understood [3-6].

Variations in the final properties of these composite structures may be caused not only by the intrinsic properties of their components (type of reinforcements and resin) but also by the resin infusion process itself, by the position of the part in relation to resin entry and outlet or by the injection temperatures used during the manufacturing process. So there is a need to identify the LRI process parameters and to quantify their effects on the mechanical properties and material health of the composite part being 
Fig. 1 Cause and effect infusion diagram for liquid resin

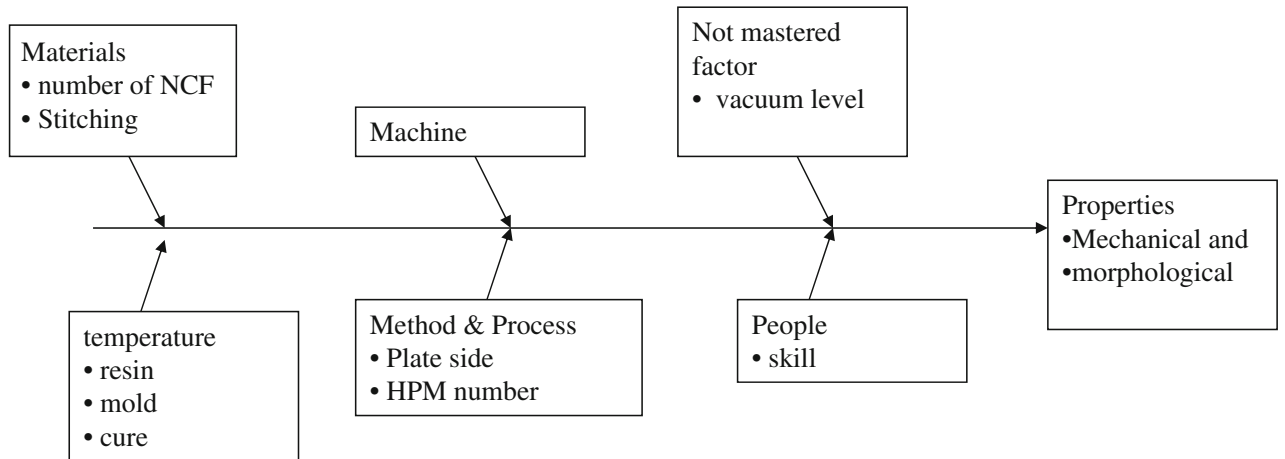

manufactured. Therefore, an impact study of these structure and process parameters on the mechanical and morphological properties of infused composites was launched, using a design of experiments (DOE) approach.

\section{Liquid resin infusion process}

A non-crimp fabric (NCF) is an assembly of several unidirectional plies with different orientations (Fig. 2). A preform is a fibre skeleton of the future part and can be made from non-crimp fabric.

The process of "liquid resin infusion" belongs to the family of liquid composite manufacturing processes, such as resin transfer moulding (RTM). This method has many variations [2]. Its basic principle is to infuse a dry fibre preform (Fig. 3) with a liquid resin through a high-porous medium by means of a vacuum pump (Figs. 4 and 5). A high-porous medium (HPM) is a medium whose permeability is much greater than that of the preform. It speeds up the arrival of the resin along the surface of the part. The resin progresses by gravity through the thickness and simultaneously by pressure gradient through the length. To summarise, the resin infuses through the combined effects of vacuum, temperature and gravity with a velocity that varies during infusion.

\subsection{Advantages}

The use of dry preforms instead of pre-pregs is an advantage for the incorporation of reinforcement in the direction orthogonal to the plane. Stitching is used to improve the behaviour on impact and compression after impact of aerospace carbon/epoxy composite [7]. The infusion process allows the use of preforms strengthened in their thickness by stitching, with minimal in-plane thread damage.

The upper part of the mould is made of a plastic film (Fig. 4). The use of this film makes this process relatively low cost (for tooling) in the manufacture of large structures, compared to other methods that use rigid metallic moulds. In addition, the use of NCF allows four (or more) plies to be draped simultaneously, which is obviously of great economic interest. The transparency of the film allows the resin flow to be viewed and also enables the use of infrared heating. It is a process for manufacturing high-performance composites, particularly for the aerospace industry, allowing high fibre volume contents $(60 \%)$ to be obtained.

\subsection{Drawbacks}

The major drawback of the process, resulting from the use of a flexible cover, is the difficulty in controlling the thickness of the manufactured part. Another drawback could also

Fig. 2 Stacking sequence with two NCF and four NCF

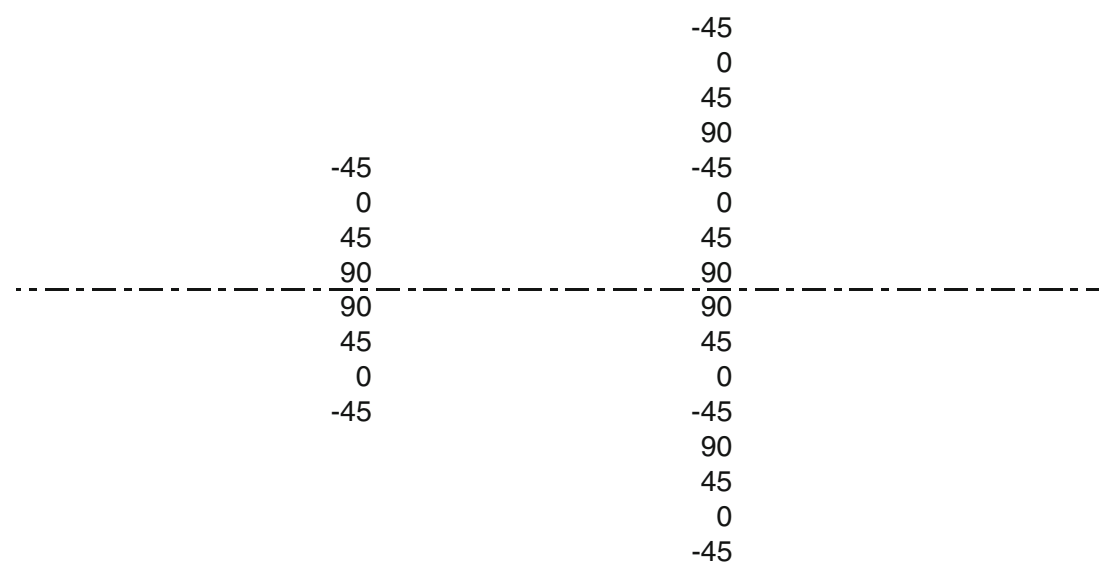




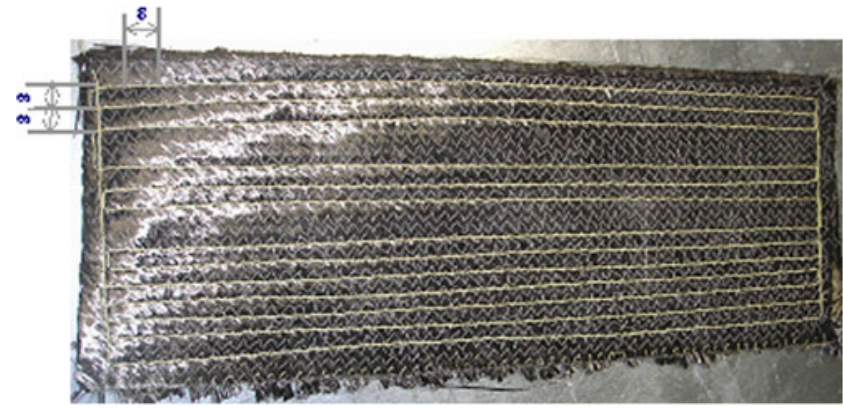

Fig. 3 Stitched preform (assembly of NCF)

be that it requires the use of an autoclave, or of an oven, which is expensive. For this reason, in this study, the curing is carried out without these costly devices.

\section{Selection of design-of-experiment parameters}

The parameters ruling liquid resin infusion quality can be determined by bibliographical study and by laboratory expertise in LRI processes. The parameters are classified into three groups:

1. Texture of reinforcement

2. Process configuration

3. Process temperatures

\subsection{Texture of reinforcement}

The potential parameters are the preform architecture (woven, knitted, the presence of transverse reinforcements: stitched or nailed), the nature of the powder binder on the plies of fabric and finally the stacking sequence itself. The rate or type of thermoplastic powder (used as a binder) usually contributes to the quality of the material and has an effect on the properties of the composite, especially the impact properties. For this study, the powder contained in

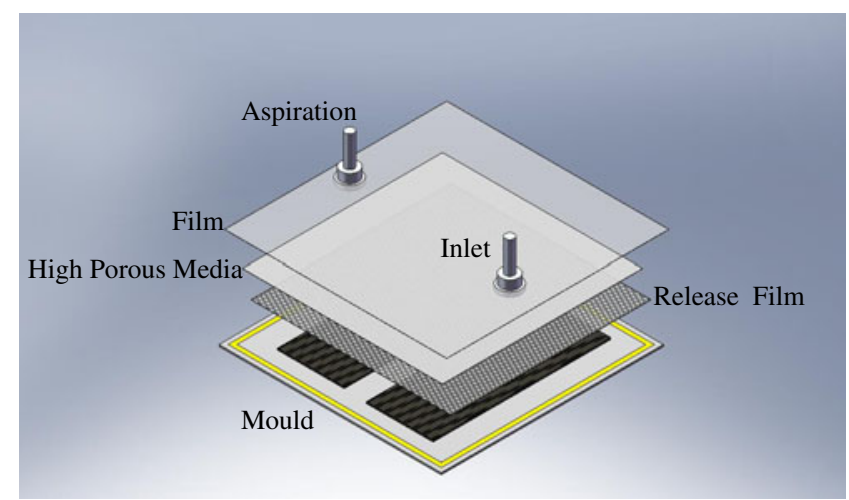

Fig. 4 Fabrication layout for liquid resin infusion

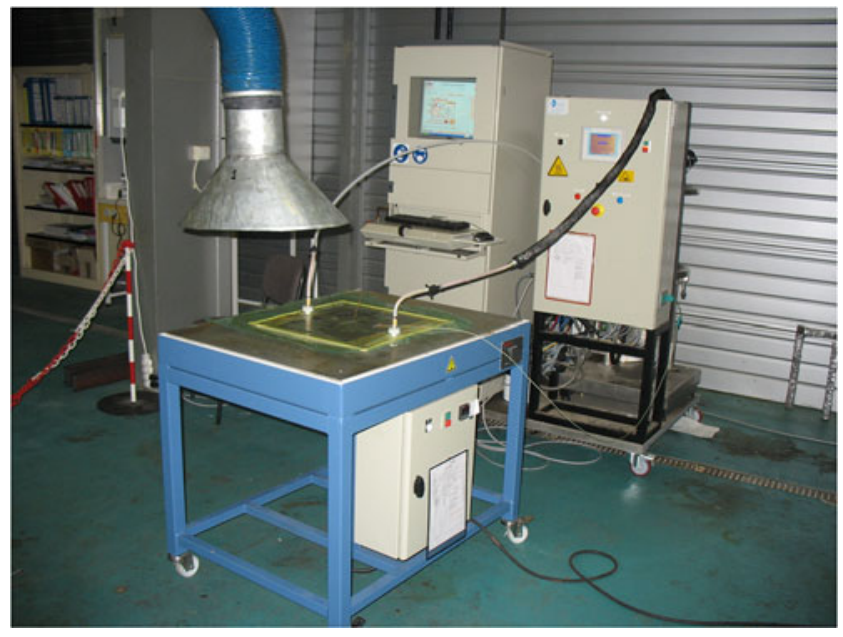

Fig. 5 Experimental device used in the manufacture of plates

the preform, manufactured by SAERTEX, is intrinsic to the reinforcement. This setting will not be among the parameters analysed.

A very effective way to improve the low-velocity impact resistance of a composite (the extent of the damaged area and residual strength on compression) is to use reinforcement in the direction orthogonal to the plane of the composite [7]. The stitching of the preform has a great potential impact on the quality and mechanical properties of composites, both during the infusion process, through the flow of the resin in the vicinity of the stitching threads and also by displacement and weaving in plane threads.

The number of NCFs is an influential parameter because of its important effects on the mechanical properties of the composite structure, either directly or through interaction with other parameters such as the number of high-porous media. A priori, its effects are important on tension or compression properties. In this study, the texture of the reinforcement, as a group of manufacturing parameters, consists in the number of NCFs $\left(N_{\mathrm{NCF}}\right)$ forming the preform and stitching $\left(C_{\mathrm{O}}\right)$.

Finally, with regard to texture, two significant parameters, $C_{\mathrm{O}}$ and $N_{\mathrm{NCF}}$, will be considered. These parameters have only two levels: the presence or absence of stitching and two or four NCFs.

\subsection{Process configuration}

Several authors [3-6] conclude that the vacuum level obtained in the cavity is an important parameter for obtaining a better quality of materials for liquid composite moulding. This vacuum level is the value of the absolute pressure in the cavity of the mould (between the vacuum cover and the inferior metallic half of the mould, see Fig. 4). Experiments 
conducted on LRI have shown that achieving a good level of vacuum depends on the tightness in the cavity during the manufacturing process. The sealing of the sheet is obtained by mean of mastic. It is not possible to set an absolute pressure in this study, and the pressure will vary (randomly, in a sense) based on the quality of assembly and sealing. For this reason, the level-of-vacuum parameter is measured during manufacture and is part of the list of parameters (variables) to be studied.

The location of the structure relative to resin injection points is a factor of variability in the composite properties (as a consequence of resin velocity and of plate thickness). The plate side, through the pressure gradient present along part of it, should influence the thickness (and thus the fibre volume content) of the composite being manufactured [8]. Thus, the location of the plate (plate side) has an effect a priori on the volume fraction of the fibres and the porosity of the composites. Porosity volume content and fibre volume content are well known in composites as determinants of their mechanical properties [9]. In this study, the numbers are determined at the entry point of the resin and at the point of void aspiration. Thus, two peripheral points are used. One is the entry of the resin, and the other is at the vacuum aspiration point of the cavity. Figure 4 shows a preform placed on the resin injection side and another placed on the side of the suction of the vacuum. Both locations will be considered in the analysis. The binary variable vacuum side/injection side is used as a parameter. The $C_{\mathrm{p}}$ variable (plate side) will evaluate changes in mechanical properties and the stability of the thickness along the structure.

The HPM is also a characteristic parameter of the flow of the resin for the manufacture of composite structures by VIP. HPM is also identified as a parameter of influence a priori. It could affect the properties of the composite in a unique way or by interaction with the number of layers of reinforcing fibres [3] (NCF here). The identification of this parameter as an impact factor is recent. Its inclusion in the analysis will enable better monitoring of its effects.

Finally, there are four significant parameters: $C_{\mathrm{p}}, N_{\mathrm{v}}$, $N_{\text {HPM }}$ and Int. These parameters can take only two states (Table 1).

\subsection{Process temperatures}

The process temperatures are the mould temperature, the injection temperature of the resin and the curing temperature of the laminate. The flow velocity of resin infusion depends on the pressure gradient reached under the plastic film (between the vacuum plastic film and the lower part of the mould). It also depends on the resin viscosity, on the permeability of the HPM and NCF, on the number of NCFs and on the number of layers of the to be infused high-porous media.
Table 1 Factors and levels

\begin{tabular}{llll}
\hline Factor & Abbreviation & Low level & High level \\
\hline $\begin{array}{l}\text { Stitching of preform } \\
\text { Cure temperature }\end{array}$ & $C_{\mathrm{o}}$ & Non-stitched (-1) & Stitched (1) \\
$\left.\quad{ }^{\circ} \mathrm{C}\right)$ & 160 & 180 \\
$\begin{array}{l}\text { Resin temperature } \\
\left({ }^{\circ} \mathrm{C}\right)\end{array}$ & $T_{\mathrm{r}}$ & 60 & 80 \\
$\begin{array}{l}\text { Mould temperature } \\
\left({ }^{\circ} \mathrm{C}\right)\end{array}$ & $T_{\mathrm{m}}$ & 100 & 120 \\
$\begin{array}{l}\text { Plate side } \\
\text { Number of }\end{array}$ & $C_{\mathrm{p}}$ & Injection $(-1)$ & Vacuum (1) \\
$\quad$ high-porous media & $N_{\mathrm{HPM}}$ & 1 & 2 \\
$\begin{array}{l}\text { Number of NCF } \\
\text { Interaction NCF }\end{array}$ & $N_{\mathrm{NCF}}$ & 2 & 4 \\
$\quad$ Int & $2-2$ or 4-1 & $4-2$ or 2-1 \\
$\begin{array}{l}\text { Vacuum pressure } \\
\text { level (mbar) }\end{array}$ & $N_{\mathrm{v}}$ & 1 & 2.4 \\
\hline
\end{tabular}

Both resin temperature and mould temperature contribute in determining the viscosity of the resin and thus drive the flow velocity of the resin in the preform. This velocity is essential in the mechanism causing the formation of pores [10-12] in the filling of preforms. Once formed, pores can migrate and/or change size during the cycle [13]. Porosity, as a defect, contributes in reducing the mechanical performance of manufactured parts [14]. The number of layers of NCF and the number of HPM participate in the calculation of the resin front speed in the preform. Temperatures also determine the adhesion and wetting of carbon fibres by the resin and the displacement of fibres during filling.

The cure temperature also determines the cure level of the resin reached at the end of the cure. Temperatures are included in the study by varying their values within acceptable ranges of properties.

Finally, three significant temperature parameters $T_{\mathrm{r}}$ (injection temperature of the resin), $T_{\mathrm{m}}$ (mould temperature) and $T_{\mathrm{c}}$ (curing temperature) will be evaluated. Temperatures change in the permitted range of variation (Table 1).

\section{Experimental methodology}

\subsection{Design of experiment}

Nine variables were selected. Potentially influential factors and levels used in the study are summarised in Table 1. An introduction to the subject of DOE can be found in the literature, for example [15].

The experimental plan that includes nine columns (parameters) and 18 lines (manufacturing experience) is given in Table 2. This is a L16 Taguchi table with one test point (lines 17 and 18) added to assess and verify the model. 
Table 2 Design of experiment

\begin{tabular}{|c|c|c|c|c|c|c|c|c|c|c|}
\hline Number & Exp. & Stitching & $\begin{array}{l}\text { Number } \\
\text { of NCF }\end{array}$ & $\begin{array}{l}\text { Temp. } \\
\text { injection }\left({ }^{\circ} \mathrm{C}\right)\end{array}$ & $\begin{array}{l}\text { Interaction } \\
\text { NCF and HPM }\end{array}$ & $\begin{array}{l}\text { Mould } \\
\text { temp. }\left({ }^{\circ} \mathrm{C}\right)\end{array}$ & $\begin{array}{l}\text { Number } \\
\text { of HPM }\end{array}$ & $\begin{array}{l}\text { Cure } \\
\text { temp. }\left({ }^{\circ} \mathrm{C}\right)\end{array}$ & Plate side & $\begin{array}{l}\text { Vacuum pressure } \\
\text { level (mbar) }\end{array}$ \\
\hline 1 & $1 \mathrm{~V}$ & With & 2 & 60 & 1 & 120 & 2 & 160 & Vacuum & 1.2 \\
\hline 2 & $1 \mathrm{I}$ & With & 2 & 60 & 1 & 120 & 2 & 160 & Injection & 1.2 \\
\hline 3 & $2 \mathrm{~V}$ & With & 2 & 60 & 2 & 100 & 1 & 180 & Vacuum & 1.1 \\
\hline 4 & $2 \mathrm{I}$ & With & 2 & 60 & 2 & 100 & 1 & 180 & Injection & 1.1 \\
\hline 5 & $3 \mathrm{~V}$ & With & 4 & 80 & 1 & 120 & 1 & 180 & Vacuum & 1.4 \\
\hline 6 & $3 I$ & With & 4 & 80 & 1 & 120 & 1 & 180 & Injection & 1.4 \\
\hline 7 & $4 \mathrm{~V}$ & With & 4 & 80 & 2 & 100 & 2 & 160 & Vacuum & 1.1 \\
\hline 8 & $4 \mathrm{I}$ & With & 4 & 80 & 2 & 100 & 2 & 160 & Injection & 1.1 \\
\hline 9 & $5 \mathrm{~V}$ & Without & 2 & 80 & 1 & 100 & 2 & 180 & Vacuum & 1.3 \\
\hline 10 & $5 \mathrm{I}$ & Without & 2 & 80 & 1 & 100 & 2 & 180 & Injection & 1.3 \\
\hline 11 & $6 \mathrm{~V}$ & Without & 2 & 80 & 2 & 120 & 1 & 160 & Vacuum & 1.1 \\
\hline 12 & $6 \mathrm{I}$ & Without & 2 & 80 & 2 & 120 & 1 & 160 & Injection & 1.1 \\
\hline 13 & $7 \mathrm{~V}$ & Without & 4 & 60 & 1 & 100 & 1 & 160 & Vacuum & 1.4 \\
\hline 14 & $7 \mathrm{I}$ & Without & 4 & 60 & 1 & 100 & 1 & 160 & Injection & 1.4 \\
\hline 15 & $8 \mathrm{~V}$ & Without & 4 & 60 & 2 & 120 & 2 & 180 & Vacuum & 2.4 \\
\hline 16 & $8 \mathrm{I}$ & Without & 4 & 60 & 2 & 120 & 2 & 180 & Injection & 2.4 \\
\hline 17 & $9 \mathrm{~V}$ & Without & 4 & 70 & 2 & 110 & 2 & 170 & Vacuum & 1.7 \\
\hline 18 & 9I & Without & 4 & 70 & 2 & 110 & 2 & 170 & Injection & 1.7 \\
\hline
\end{tabular}

This table was chosen because it allows the investigation of the linear effects of the factors studied and the interaction between the number of NCFs and the number of HPM. This is possible at an acceptable experimental cost. Factor variation between a low and a high level is used to evaluate the effect of the factor on the desired quality.

The vacuum level is a particular factor, since it is not controlled but measured during manufacture. However, it is used as an entry in the multilinear regression analysis of test results. This is a potential problem because the vacuum-level factor does not satisfy the orthogonality condition in relation to other factors. An explanation of orthogonality in DOE can also be found in the literature [15].

\subsection{Manufacture of plates}

\subsubsection{Production of preforms}

The preforms are made of two or four NCFs made of intermediate modulus carbon fibre Tenax IMS 5131 fed with one or two high-porous media. The stacking sequences used are $[-45 / 0 / 45 / 90] \mathrm{s}$ and $[-45 / 0 / 45 / 90 /-45 / 0 / 45 / 90] \mathrm{s}$ (Fig. 2).

NCFs of the intermediate modulus carbon fibre (fibre IMS 5131) were cut and, in some cases, stitched (Fig. 3). The stitching was done with an industrial sewing machine with the Kevlar thread (for visibility), in parallel straight lines in the direction of the length with the lock stitch modified. The distance between two successive points was $8 \mathrm{~mm}$, and spacing between two lines was also $8 \mathrm{~mm}$. Preforms were arranged as shown in Fig. 4. The vacuum was executed until a vacuum level of less than 3 mbar was reached in the pressure sensor located at the vacuum pump.

\subsubsection{Preforms infusion}

The manufacture of composite plates was carried out as follows: RTM6 resin was preheated to the injection temperature $\left(60\right.$ or $\left.80{ }^{\circ} \mathrm{C}\right)$ and systematically degassed under vacuum. The mould was heated to the temperature of the mould $\left(100\right.$ or $120{ }^{\circ} \mathrm{C}$ ) and then infusion was performed. The cure cycles were applied for either $75 \mathrm{~min}$ at $160{ }^{\circ} \mathrm{C}$ or $60 \mathrm{~min}$ at $180{ }^{\circ} \mathrm{C}$. As a validation trial, a cure cycle of $70 \mathrm{~min}$ at $170{ }^{\circ} \mathrm{C}$ was used. During each cycle, two plates were made of $400 \times 150 \mathrm{~mm}^{2}$, one a vacuum-side plate and the other an injection-side plate (see Fig. 4).

The cross-linking of the resin during manufacture was carried out in our study without autoclave using a heating table (Fig. 5). The device also allowed LRI infrared cure of the composite [16].

No post-curing was carried out so as not to blur the effects of cure temperature in the laminate during the analysis. Subsequently, the plates were cut into the mechanical test specimens. 
Table 3 Norms of tests

\begin{tabular}{lcl}
\hline Trial & $\begin{array}{l}\text { Number of } \\
\text { tested samples }\end{array}$ & Norm \\
\hline Traction & 3 & NF EN ISO 517-4 \\
Compression & 3 & NF EN ISO 14126 \\
$\begin{array}{l}\text { ILSS } \\
\text { Fibre volume content, void } \\
\begin{array}{c}\text { content } \\
\text { Glass transition temperature }\end{array}\end{array}$ & 3 & NF EN ISO 14130 \\
\hline
\end{tabular}

\subsection{Tests and measurements}

The mechanical test specimens were cut to test the composite materials, as shown in Table 3 and Fig. 6. Mechanical tests were performed according to composite standards. In total, 306 samples were cut into 18 plates. Results of testing appear in Tables 5 and 6 .

\section{Results of analysis}

\subsection{Statistical analysis of process effects}

Multilinear regression was performed on the different responses, depending on the parameters coded ( -1 for low level, 1 for high level), as shown in Table 4. This coding made it possible to obtain directly comparable effects, with all entries ranging from -1 to 1 . The effect was the expected change in output caused by a variation between -1 and 1 from the entrance. This was twice the estimated coefficients that appear in Eqs. 1-7, expressed in terms of coded variables. These coefficients were calculated by multilinear regression, by the method of least squares. A Fischer test ( $F$ test) was done to test the model as a whole. We tested the hypothesis of nullity of all coefficients with an $F$ test. If the
$P$ value of the $F$ test is lower than the $5 \%$ significance level, the model is significant at $5 \%$, that is to say we can reject the hypothesis that all coefficients are zero, allowing us to interpret the model coefficients. A Student's $t$ test was done, in order to differentiate the statistically significant parameters from other parameters. According to the Student's $t$ test, a $P$ value could be calculated for each parameter. Parameters not significant at $5 \%$ (with a $P$ value higher than $5 \%$ ) were eliminated one by one, so as to keep only the parameters that were considered statistically significant (with a $P$ value lower than $5 \%$ ). Multilinear regression was iterated on the remaining parameters until the model retained only significant parameters. This process is called backward elimination. It is necessitated by the presence of the uncontrolled factor, "vacuum level", which does not conform in orthogonality with other factors. This approach allows a step-bystep analysis and is one way of achieving this objective; it is not the only one. If a parameter has a $P$ value close to $5 \%$ but slightly higher, it is said to be of little significance; if it is lower than $5 \%$, it is said to be significant $(\mathrm{S})$, and if a parameter has a $P$ value lower than $1 \%$, it is said to be very significant (VS). Thus, the lower the $P$ value, the more significant the parameter. Table 7 summarises the statistical significance of process parameters on properties.

Interlaminar shear strength (ILSS) values corresponding to lines 7 and 8 of Table 5 were excluded from the analysis because they were abnormally low and would have distorted the analysis (the aim of the study was to look for important mechanical properties including shear). It should be understood that the DOE approach combines not only statistical and mathematical calculations on the one hand but also the expertise in the process on the other hand. Expertise guides the decision to study different parameters and different models that can be mathematically similar but have a different meaning for the process. Linear regression allows the calculation to be made in the case of missing (or outlier) data. A Taguchi-type calculation would not have allowed this.
Fig. 6 Cutting plan of specimens

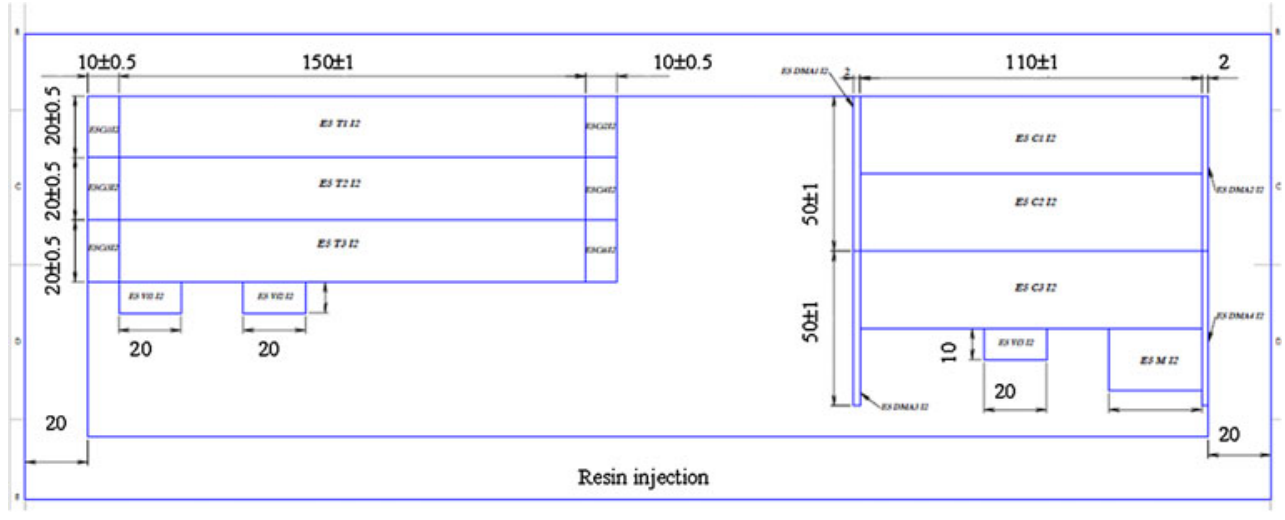


Table 4 Coded design of experiment

\begin{tabular}{|c|c|c|c|c|c|c|c|c|c|c|}
\hline Number & Exp. & Stitching & $\begin{array}{l}\text { Number } \\
\text { of NCF }\end{array}$ & $\begin{array}{l}\text { Temp. } \\
\text { injection }\left({ }^{\circ} \mathrm{C}\right)\end{array}$ & $\begin{array}{l}\text { Interaction } \\
\text { NCF and HPM }\end{array}$ & $\begin{array}{l}\text { Mould } \\
\text { temp. }\left({ }^{\circ} \mathrm{C}\right)\end{array}$ & $\begin{array}{l}\text { Number } \\
\text { of HPM }\end{array}$ & $\begin{array}{l}\text { Cure temp. } \\
\left({ }^{\circ} \mathrm{C}\right)\end{array}$ & Plate side & $\begin{array}{l}\text { Vacuum pressure } \\
\text { level (mbar) }\end{array}$ \\
\hline 1 & $1 \mathrm{~V}$ & 1 & -1 & -1 & -1 & 1 & 1 & -1 & -1 & -0.85 \\
\hline 2 & $1 \mathrm{I}$ & 1 & -1 & -1 & -1 & 1 & 1 & -1 & 1 & -0.85 \\
\hline 3 & $2 \mathrm{~V}$ & 1 & -1 & -1 & 1 & -1 & -1 & 1 & -1 & -1.00 \\
\hline 4 & $2 \mathrm{I}$ & 1 & -1 & -1 & 1 & -1 & -1 & 1 & 1 & -1.00 \\
\hline 5 & $3 \mathrm{~V}$ & 1 & 1 & 1 & -1 & 1 & -1 & 1 & -1 & -0.54 \\
\hline 6 & $3 I$ & 1 & 1 & 1 & -1 & 1 & -1 & 1 & 1 & -0.54 \\
\hline 7 & $4 \mathrm{~V}$ & 1 & 1 & 1 & 1 & -1 & 1 & -1 & -1 & -1.00 \\
\hline 8 & $4 \mathrm{I}$ & 1 & 1 & 1 & 1 & -1 & 1 & -1 & 1 & -1.00 \\
\hline 9 & $5 \mathrm{~V}$ & -1 & -1 & 1 & -1 & -1 & 1 & 1 & -1 & -0.69 \\
\hline 10 & $5 \mathrm{I}$ & -1 & -1 & 1 & -1 & -1 & 1 & 1 & 1 & -0.69 \\
\hline 11 & $6 \mathrm{~V}$ & -1 & -1 & 1 & 1 & 1 & -1 & -1 & -1 & -1.00 \\
\hline 12 & $6 \mathrm{I}$ & -1 & -1 & 1 & 1 & 1 & -1 & -1 & 1 & -1.00 \\
\hline 13 & $7 \mathrm{~V}$ & -1 & 1 & -1 & -1 & -1 & -1 & -1 & -1 & -0.08 \\
\hline 14 & 7I & -1 & 1 & -1 & -1 & -1 & -1 & -1 & 1 & -0.08 \\
\hline 15 & $8 \mathrm{~V}$ & -1 & 1 & -1 & 1 & 1 & 1 & 1 & -1 & 1.00 \\
\hline 16 & $8 \mathrm{I}$ & -1 & 1 & -1 & 1 & 1 & 1 & 1 & 1 & 1.00 \\
\hline 17 & $9 \mathrm{~V}$ & -1 & 1 & 0 & 1 & 0 & 1 & 0 & -1 & 0.00 \\
\hline 18 & 9I & -1 & 1 & 0 & 1 & 0 & 1 & 0 & 1 & 0.00 \\
\hline
\end{tabular}

Each property is modelled using a linear model. The interaction between the number of NCFs and the number of HPM is built into the model. The model applied for the three mechanical properties and the four morphological properties is linear.
The best linear models found after iterations are the following:

$$
\begin{aligned}
& \sigma_{t}=747.97+24.47 C_{p} \\
& \sigma_{c}=466.57+22.96 C_{o}-20 N_{H P M}
\end{aligned}
$$

Table 5 Mechanical experimental results

\begin{tabular}{lcrcccccc}
\hline & Number & Exp. & $\sigma_{\mathrm{t}}(\mathrm{MPa})$ & $\operatorname{Std} \operatorname{dev}\left(\sigma_{\mathrm{t}}\right)$ & $\sigma_{\mathrm{c}}(\mathrm{MPa})$ & $\operatorname{Std} \operatorname{dev}\left(\sigma_{\mathrm{c}}\right)$ & $\tau_{\max }(\mathrm{MPa})$ & $\mathrm{Std} \operatorname{dev}\left(\tau_{\max }\right)$ \\
\hline Stitched & 1 & $1 \mathrm{~V}$ & 692.76 & 13.78 & 489.22 & 40.84 & 40.30 & 1.21 \\
Stitched & 2 & $1 \mathrm{I}$ & 780.95 & 62.99 & 438.17 & 20.22 & 45.28 & 1.61 \\
Stitched & 3 & $2 \mathrm{~V}$ & 759.74 & 66.15 & 444.67 & 67.09 & 46.21 & 1.18 \\
Stitched & 4 & $2 \mathrm{I}$ & 742.26 & 37.96 & 550.23 & 33.94 & 37.94 & 2.71 \\
Stitched & 5 & $3 \mathrm{~V}$ & 789.84 & 48.59 & 496.95 & 43.44 & 44.69 & 4.96 \\
Stitched & 6 & $3 \mathrm{I}$ & 789.01 & 33.07 & 558.38 & 19.08 & 35.40 & 2.82 \\
Stitched & 7 & $4 \mathrm{~V}$ & 741.87 & 23.83 & 487.17 & 49.82 & 15.04 & 2.03 \\
Stitched & 8 & $4 \mathrm{I}$ & 702.96 & 20.67 & 452.26 & 0.79 & 13.12 & 0.73 \\
Non-stitched & 9 & $5 \mathrm{~V}$ & 740.45 & 24.80 & 422.17 & 11.89 & 36.60 & 2.64 \\
Non-stitched & 10 & $5 \mathrm{I}$ & 772.52 & 16.34 & 451.67 & 46.10 & 36.33 & 2.65 \\
Non-stitched & 11 & $6 \mathrm{~V}$ & 577.47 & 59.50 & 400.44 & 2.86 & 31.23 & 4.44 \\
Non-stitched & 12 & $6 \mathrm{I}$ & 805.24 & 57.95 & 433.08 & 43.53 & 39.62 & 2.41 \\
Non-stitched & 13 & $7 \mathrm{~V}$ & 753.92 & 60.18 & 487.25 & 72.10 & 42.82 & 4.16 \\
Non-stitched & 14 & $7 \mathrm{I}$ & 784.43 & 64.31 & 487.29 & 45.32 & 41.65 & 5.34 \\
Non-stitched & 15 & $8 \mathrm{~V}$ & 727.16 & 9.24 & 439.64 & 44.54 & 46.31 & 4.10 \\
Non-stitched & 16 & $8 \mathrm{I}$ & 802.15 & 19.68 & 393.11 & 54.57 & 41.08 & 6.21 \\
\hline
\end{tabular}




$$
\tau_{\max }=42.84+3.88 N_{v}+1.95 C_{o}
$$

$$
T_{g}=160.12+15.91 T_{c}-8.65 C_{o}-10.93 N v+5.46 T_{m}
$$

$V_{p}=1.12+0.21 T_{C}+0.20 T_{i}+0.32 N_{v}$

$$
\begin{aligned}
V_{f}= & 61.16-0.93 T_{m}+0.83 T_{i}-0.79 \operatorname{Int}_{N C F, H P M} \\
& -0.76 N_{H P M}-0.50 C_{o}
\end{aligned}
$$

$$
\begin{aligned}
h= & 3.14+0.90 N_{N C F}+0.07 \operatorname{Int}_{N C F, H P M}+0.20 N_{v} \\
& +0.08 C_{o}+0.04 N_{H P M}+0.05 T_{i}
\end{aligned}
$$

Another way to give these results is to draw the effect plots (Figs. 7, 8, 9, 10,11 and 12). These plots illustrate how big the change of the property will be, with a change of parameter between low level and high level. These plots are main-factor-effects plots, and factors are only represented when they are significant (significance level $5 \%$ ). These graphs show the variation associated with a parameter, and the smallest variation that appears on these graphs gives an idea of the residual dispersion of the studied phenomenon. For example, in Fig. 10 or Eq. 6, a change of fibre volume content lower than $1 \%(2 \times 0.5$, the smallest coefficient in absolute value) is considered as not significant, and so factors that produce lower change are not shown.

Fibre volume contents $\left(V_{\mathrm{f}}\right)$ achieved in these test campaigns are important, and porosity volume contents are low. The fibre volume content and porosity volume content $\left(V_{\mathrm{p}}\right)$ are as expected for aerospace structural composites.

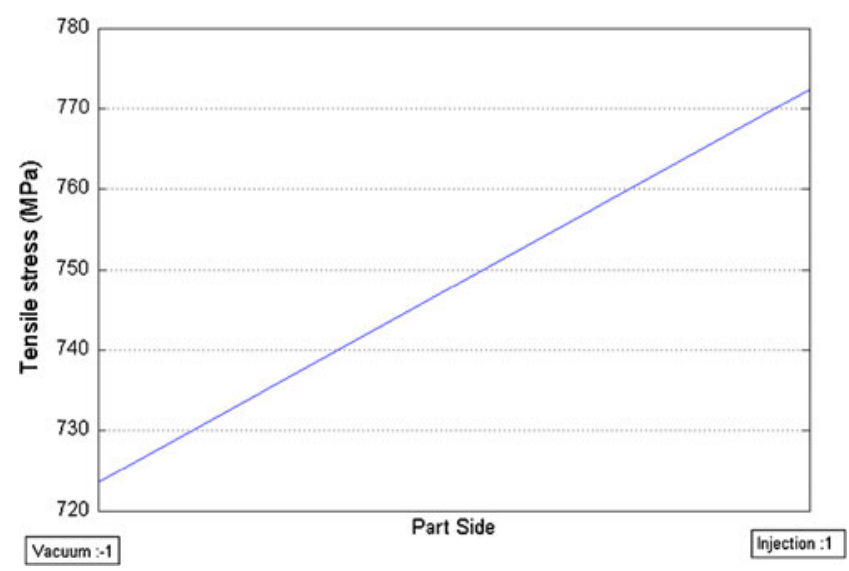

Fig. 7 Side-of-the-plate effect on the tensile strength

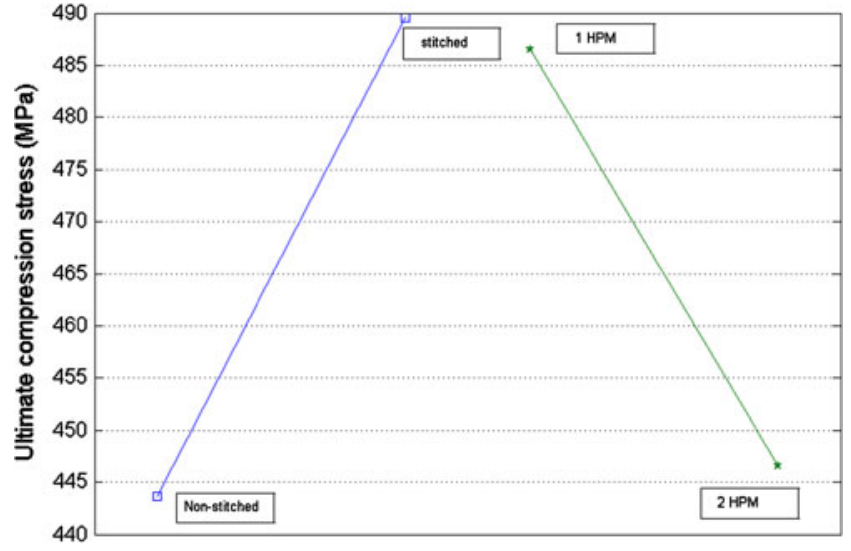

Fig. 8 Compressive strength main effects plot

The shear strengths are low for the resin used, which is due to the lack of post cure. These results will be analysed in relation to the group of parameters.

\subsection{Influence of preform nature}

Preform nature includes the number of layers of carbon $\mathrm{NCFs}\left(N_{\mathrm{NCF}}\right)$ and the stitching of the preform. Statistical analysis of the results identified two types of parameter that influence the morphological and mechanical properties of the laminates infused (Tables 6).

\subsubsection{Number of NCFs}

The number of carbon NCFs $\left(N_{\mathrm{NCF}}\right)$ influenced only the thickness ( $h$, Eq. 7), but it influenced it very significantly by making it grow naturally when this parameter was doubled. So there was an increase of $80 \%$ in the thickness of the laminate due to the sole effect of the number of NCFs. The additional $20 \%$ that would double the thickness was

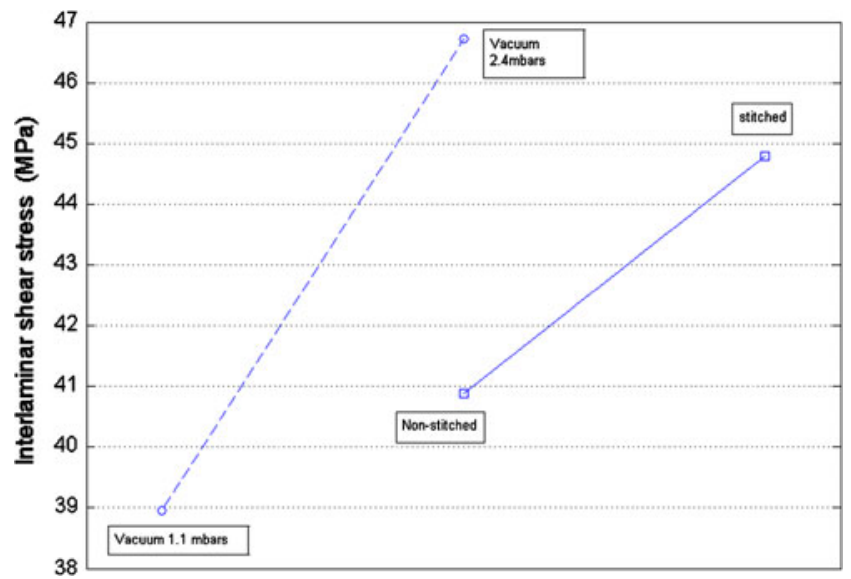

Fig. 9 Interlaminar shear stress main effects plot 


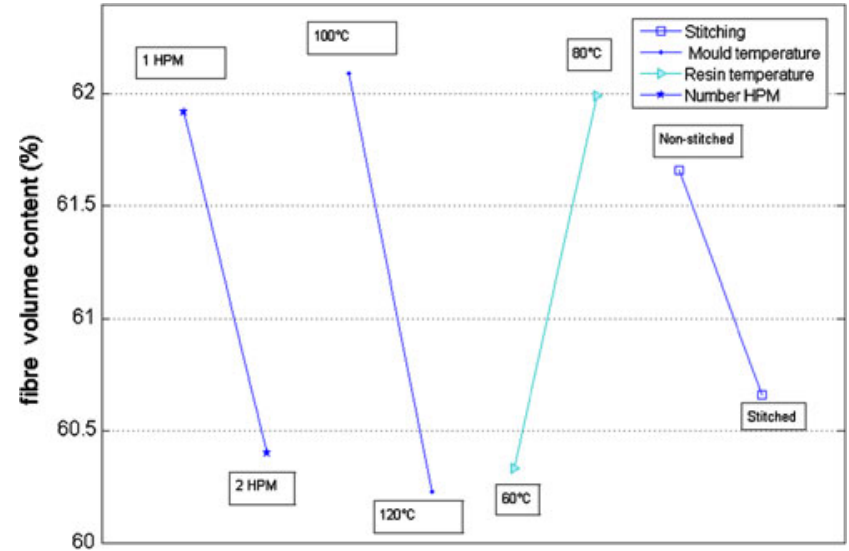

Fig. 10 Fibre volume content main effects plot

generated by an effect of compaction of the structure during the vacuum process [17-19]. In other words, a greater number of plies were more compacted in the process. One could have surmised that the side of the plate (vacuum or injection) would impact on the fibre volume content. However, the results did not show any impact. This illustrates the complexity and unpredictability of the process, which contrasts with its apparent simplicity.

\subsubsection{Stitching}

The stitching also had a VS effect (Table 7) on the compression strength, fibre volume content and thickness. The model predicts an average increase of $0.16 \mathrm{~mm}$ in thickness in the presence of stitching. Stitching of the preform creates more variation in the compressive strength $\left(\sigma_{\mathrm{c}}\right.$, Eq. 2$)$, the interlaminar shear strength $\left(\tau_{\max }\right.$ or ILSS, Eq. 3), glass transition temperature $\left(T_{\mathrm{g}}\right.$, Eq. 4$)$ and fibre volume fraction $\left(V_{\mathrm{f}}\right.$, Eq. 6) of infused laminates. The influence of stitching

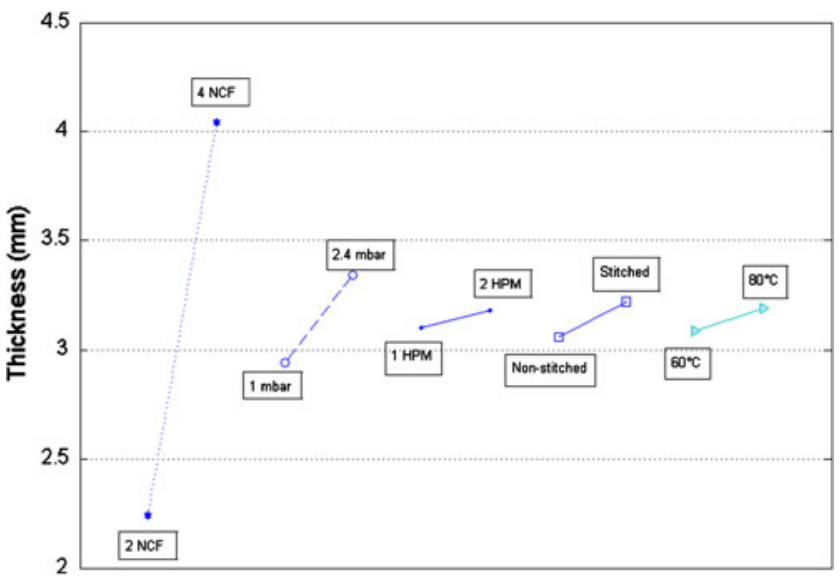

Fig. 11 Thickness main effect plot

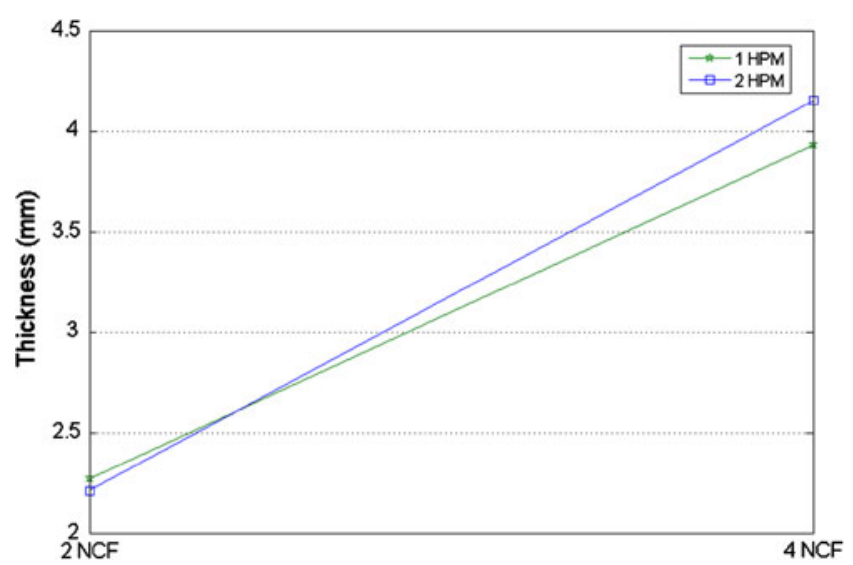

Fig. 12 Interaction graph for thickness

on the glass transition temperature was extraordinary and it must be borne in mind that this may be an experimental artefact. On the other hand, the influence of stitching on ILSS, or compressive strength, was expected.

\subsection{Influence of process configuration}

The group "process configuration" contains the number of high-porous media, the plate side and the vacuum level. Statistical analysis revealed the significance of these parameters (Table 7).

\subsubsection{HPM}

The maximum compressive strength was lower when using two HPM instead of one ( $8.57 \%$ of variation). The thickness was also greater and the fibre volume content was lower. This can be interpreted as the compaction of the preform being made more difficult when resin flows quickly through the mould.

\subsubsection{Plate side}

The maximum tensile strength increased when going from vacuum side to injection side $(6.54 \%)$. This was the only response that was influenced by the plate-side factor. Parts produced close to the injection side have better tensile behaviour.

\subsubsection{Vacuum pressure}

The interlaminar shear strength was lower for a lower vacuum pressure (18\% of variation). This is not related to porosity as the two evolve in opposite directions, but it could be the consequence of a lower $T_{\mathrm{g}}$. This result was confirmed by the low value of interlaminar shear strength found in this study. 
Table 6 Morphological properties results

\begin{tabular}{|c|c|c|c|c|c|c|c|c|c|c|}
\hline & Number & Exp. & $T_{\mathrm{g}}\left({ }^{\circ} \mathrm{C}\right)$ & $\operatorname{Std} \operatorname{dev}\left(T_{\mathrm{g}}\right)$ & $h(\mathrm{~mm})$ & Std dev $(h)$ & $V_{\mathrm{f}}(\%)$ & $\begin{array}{l}\text { Std dev } \\
\left(V_{\mathrm{f}}\right)\end{array}$ & $V_{\mathrm{p}}(\%)$ & $\begin{array}{l}\text { Std dev } \\
\left(V_{\mathrm{p}}\right)\end{array}$ \\
\hline Stitched & 1 & $1 \mathrm{~V}$ & 121.55 & 1.77 & 2.10 & 0.09 & 59.08 & 1.24 & 0.25 & 0.21 \\
\hline Stitched & 2 & $1 \mathrm{I}$ & 114.50 & 4.95 & 2.09 & 0.06 & 59.97 & 0.21 & 0.58 & 0.07 \\
\hline Stitched & 3 & $2 \mathrm{~V}$ & 160.40 & 11.88 & 2.10 & 0.11 & 60.59 & 0.30 & 0.79 & 0.10 \\
\hline Stitched & 4 & $2 \mathrm{I}$ & 180.75 & 6.43 & 2.06 & 0.10 & 61.16 & 0.28 & 1.01 & 0.09 \\
\hline Stitched & 5 & $3 \mathrm{~V}$ & 184.75 & 4.17 & 4.02 & 0.22 & 61.60 & 0.10 & 1.24 & 0.09 \\
\hline Stitched & 6 & $3 I$ & 177.65 & 6.86 & 3.88 & 0.13 & 62.31 & 0.35 & 1.42 & 0.18 \\
\hline Stitched & 7 & $4 \mathrm{~V}$ & 140.65 & 10.96 & 4.02 & 0.10 & 61.70 & 1.22 & 1.04 & 0.11 \\
\hline Stitched & 8 & $4 \mathrm{I}$ & 119.35 & 1.34 & 4.12 & 0.08 & 58.90 & 0.37 & 1.26 & 0.07 \\
\hline Non-stitched & 9 & $5 \mathrm{~V}$ & 193.80 & 1.13 & 2.02 & 0.04 & 64.33 & 0.58 & 1.19 & 0.16 \\
\hline Non-stitched & 10 & $5 \mathrm{I}$ & 180.65 & 1.20 & 2.04 & 0.07 & 65.37 & 1.04 & 1.02 & 0.26 \\
\hline Non-stitched & 11 & $6 \mathrm{~V}$ & 161.25 & 0.21 & 2.05 & 0.05 & 61.30 & 0.26 & 0.59 & 0.16 \\
\hline Non-stitched & 12 & $6 \mathrm{I}$ & 172.55 & 1.06 & 2.04 & 0.03 & 62.11 & 0.63 & 0.73 & 0.12 \\
\hline Non-stitched & 13 & $7 \mathrm{~V}$ & 139.75 & 3.89 & 3.81 & 0.20 & 63.47 & 0.98 & 0.15 & 0.03 \\
\hline Non-stitched & 14 & 7I & 154.80 & 11.17 & 3.77 & 0.17 & 62.88 & 0.43 & 0.80 & 0.38 \\
\hline Non-stitched & 15 & $8 \mathrm{~V}$ & 182.20 & 2.55 & 4.27 & 0.07 & 57.16 & 0.19 & 2.97 & 0.27 \\
\hline Non-stitched & 16 & $8 \mathrm{I}$ & 155.00 & 6.93 & 4.18 & 0.04 & 56.64 & 0.15 & 0.18 & 0.08 \\
\hline
\end{tabular}

In Eqs. 5-7, it can be observed that there was a decrease in $V_{\mathrm{f}}$ and $T_{\mathrm{g}}$ with the increase in the configuration parameters of the process, while $V_{\mathrm{p}}$ and $h$ both increased. Indeed, an increase in thickness and degree of porosity due to a less intensive level of vacuum results in a decrease in fibre volume in the composite. If, in addition, there is the difficulty of compaction, as is the case with the presence of two high-porous media, $V_{\mathrm{f}}$ decreases further.

The part thickness is a consequence of the compaction of the preform. Compaction was found to be easier with an intensive vacuum level $(-1)$, without stitching, with one HPM, and for a resin temperature of $60{ }^{\circ} \mathrm{C}$. With one HPM and a low temperature, the resins flow slowly through the preform, which gives more time for the preform to compact. The porosity content is an image of the porosity formation and growth. A more intensive compaction prevents any potential increase in porosity.

In a composite, carbon fibres are conductive of heat and the resin acts as an insulator. Thus, a lower vacuum level would cause less compaction of the fibres and also lead to reduced thermal conductivity. This would result in poor heat conduction inside the material. This explains the decrease in the glass transition temperature of the infused laminates for less advanced vacuum levels and also for stitched preforms. The morphological properties of laminates, infused nonstitched or stitched, are always best when made with a low vacuum pressure (coded -1$)$.

\subsection{Influence of process temperatures}

The mould temperature, the resin injection temperature and resin curing temperature are the temperatures used during the manufacture of composite laminate by LRI. At least one of the parameters of this group has an influence (VS, S) on each of the morphological properties of the laminates infused (Table 7).

Increasing the mould temperature and the curing temperature caused an increase in the glass transition temperature of the laminate infused, which was predictable. In fact,

Table 7 Statistical significance of process parameters on properties (VS very significant, $\mathrm{S}$ significant, LS little significance)

\begin{tabular}{lccccccc}
\hline Process parameter & $\sigma_{\mathrm{t}}$ & $\sigma_{\mathrm{c}}$ & $\tau_{\max }$ & $T_{\mathrm{g}}$ & $V_{\mathrm{f}}$ & $V_{\mathrm{p}}$ & $h$ \\
\hline Number of NCF $\left(N_{\mathrm{NCF}}\right)$ & & & & & & & VS \\
Stitching $\left(C_{\mathrm{o}}\right)$ & & $\mathrm{VS}$ & $\mathrm{S}$ & $\mathrm{S}$ & $\mathrm{VS}$ & & $\mathrm{VS}$ \\
Number of HPM & & $\mathrm{S}$ & & & $\mathrm{VS}$ & & $\mathrm{VS}$ \\
Plate side $\left(C_{\mathrm{p}}\right)$ & $\mathrm{VS}$ & & & & & & \\
Vacuum pressure level $\left(N_{\mathrm{v}}\right)$ & & & $\mathrm{VS}$ & $\mathrm{S}$ & & $\mathrm{S}$ & $\mathrm{VS}$ \\
Mould temperature & & & & $\mathrm{LS}$ & $\mathrm{VS}$ & & \\
Injection temperature & & & & $\mathrm{VS}$ & $\mathrm{S}$ & $\mathrm{VS}$ \\
Cure temperature & & & $\mathrm{VS}$ & & $\mathrm{S}$ & \\
Interaction NCF, HPM & & & & & $\mathrm{VS}$ & & $\mathrm{VS}$ \\
\hline
\end{tabular}


Table 8 Mechanical results of experiment 9

\begin{tabular}{rrrrrrrrr}
\hline & Number & Exp. & $\sigma_{t}(\mathrm{MPa})$ & $\begin{array}{l}\text { Std dev } \\
\left(\sigma_{\mathrm{t}}\right)\end{array}$ & $\sigma_{\mathrm{c}}(\mathrm{MPa})$ & $\begin{array}{l}\text { Std dev } \\
\left(\sigma_{\mathrm{c}}\right)\end{array}$ & $\tau_{\max }(\mathrm{MPa})$ & $\begin{array}{l}\text { Std dev } \\
\left(\tau_{\max }\right)\end{array}$ \\
\hline Non-stitched & 17 & $9 \mathrm{~V}$ & 694.90 & 14.80 & 493.87 & 35.84 & 35.37 & 6.02 \\
Non-stitched & 18 & $9 \mathrm{I}$ & 790.71 & 33.30 & 473.66 & 30.51 & 39.51 & 3.12 \\
\hline
\end{tabular}

when the laminate was infused with a high mould temperature, the gap between it and the curing temperature was reduced, which increased the degree of polymerisation of the material and increased the $T_{\mathrm{g}}$. Furthermore, it is now known [11] that, in general, higher process temperatures cause an expansion of pores within the laminate. This explains the increase in $V_{\mathrm{p}}$ in the results found with the injection temperature and the curing temperature.

On the contrary, the study did not reveal any effect of temperature on the mechanical properties in tension or compression. However, two aspects need to be kept in mind:

A manual manufacturing process (such as liquid resin infusion) is dependent on the talent of the worker, technician or engineer who implements the advanced technology. Therefore, the effects of the factors that can have an influence should be linked to the level of process control (Fig. 1). The revelation of subtle trends requires a level of mastery of the process in order to control the trend. A change in process control (operator, technology) will probably affect the influence of temperature on the mechanical properties. For example, if the same study was done with the use of an autoclave or oven (which gives a better control of temperature because the influence of convection can be removed), different effects of temperature would be found. Although there are many variants of the resin infusion process, this study can bring some understanding through experimental information.

The second point is that the analysis and the models obtained are somewhat subjective. If the question is so difficult to resolve, it is first because the data are difficult to collect and then difficult to put into operation, while the trends are relatively subtle. Several models can have approximately the same level of statistical performance and a very different interpretation of the influential parameters. It should also be kept in mind that the model is not as unique as it may at first appear. The factor "vacuum level" $\left(N_{\mathrm{v}}\right)$ has some correlation with the other factors; it is the cause of bias and difficulty of analysis compared to a more classical design of experiments. One can also interpret the deviations from what might be logically expected as an expression of the random tightness of the plastic film used as a seal.

These two points could be summarised as follows: technology is important in data collection and expertise is important in the analysis of data. Without this expertise, it is extremely easy to come to a wrong conclusion, especially for small effects. The influence of one factor may hide another. For all these reasons, it is therefore always prudent to review the models obtained.

\section{Model validation}

To check the relevance of the model obtained, it was tested on a central point (experiment 9, as defined in Tables 2, 8 and 9). This point did not belong to the plan used to calculate the model.

Table 10 outlines the predicted and measured data for the morphological and mechanical properties. The comparison was performed using experiment 9, which is a quasi-central point. There is a good agreement on the mechanical properties, but not for the glass transition temperature. The predicted glass transition temperature is well below the glass transition temperature measured. The probable cause is that the vacuum cover is exposed to a condition of convective heat exchange with ambient air. Room temperature has significant changes (about 10 to $15^{\circ} \mathrm{C}$ ) from day to day in the workshop. As it stands, this is a consideration for the use of this process for the

Table 9 Morphological results of experiment 9

\begin{tabular}{|c|c|c|c|c|c|c|c|c|c|c|}
\hline & Number & Exp. & $T_{\mathrm{g}}\left({ }^{\circ} \mathrm{C}\right)$ & $\begin{array}{l}\text { Std dev } \\
\left(T_{\mathrm{g}}\right)\end{array}$ & $h(\mathrm{~mm})$ & $\begin{array}{l}\text { Std dev } \\
(h)\end{array}$ & $V_{\mathrm{f}}(\%)$ & $\begin{array}{l}\text { Std dev } \\
\left(V_{\mathrm{f}}\right)\end{array}$ & $V_{\mathrm{p}}(\%)$ & $\begin{array}{l}\text { Std dev } \\
\left(V_{\mathrm{p}}\right)\end{array}$ \\
\hline Non-stitched & 17 & $9 \mathrm{~V}$ & 182.20 & 0.28 & 3.97 & 0.094 & 61.47 & 0.432 & 1.44 & 0.275 \\
\hline Non-stitched & 18 & 9I & 179.70 & 0.42 & 4.00 & 0.069 & 61.84 & 3.805 & 2.03 & 0.028 \\
\hline
\end{tabular}


Table 10 Synthesis on predicted/measured agreement for experiment 9

\begin{tabular}{lccll}
\hline & Calculated & Measured & $\begin{array}{l}\text { Measured } \\
\text { standard } \\
\text { deviation }\end{array}$ & Agreement \\
& & & & \\
\hline Traction (MPa) (17) & 723.5 & 694.9 & 14.8 & Good \\
Traction (MPa) (18) & 772.44 & 790.71 & 33.3 & Good \\
Compression (MPa) & 463.61 & 493.87 & 35.84 & Good \\
$(17)$ & & 473.66 & 39.51 & Good \\
Compression (MPa) & 463.61 & & & \\
$(18)$ & 40.89 & 35.37 & 6.02 & Good \\
shear (MPa) (17) & 40.89 & 39.51 & 3.012 & Good \\
shear (MPa) (18) & 168.8 & 182.2 & 0.28 & Bad \\
$T_{\mathrm{g}}\left({ }^{\circ} \mathrm{C}\right)(17)$ & 168.8 & 179.7 & 0.42 & Bad \\
$T_{\mathrm{g}}\left({ }^{\circ} \mathrm{C}\right)(18)$ & 1.1 & 1.4 & 0.275 & Good \\
$V_{\mathrm{p}}(\%)(17)$ & 1.1 & 2.0 & 0.028 & Bad \\
$V_{\mathrm{p}}(\%)(18)$ & 61.6 & 61.5 & 0.432 & Good \\
$V_{\mathrm{f}}(\%)(17)$ & 61.6 & 61.8 & 0.432 & Good \\
$V_{\mathrm{f}}(\%)(18)$ & 3.99 & 3.97 & 0.094 & Good \\
$h(\mathrm{~mm})(17)$ & 3.99 & 4 & 0.069 & Good \\
$h(\mathrm{~mm})(18)$ & & & & \\
\hline
\end{tabular}

manufacture of high performance composites. More attention should be paid to this aspect in the future.

\subsection{Multi-quality optimisation}

It may be interesting to know, in general terms, what the most favourable manufacturing conditions are. To do so, we

Table 11 Coded mechanical performances

\begin{tabular}{lrlll}
\hline Number & Exp. & $\sigma_{\mathrm{t}}$ & $\sigma_{\mathrm{c}}$ & $\tau_{\max }$ \\
\hline 1 & $1 \mathrm{~V}$ & 0.51 & 0.58 & 0.82 \\
2 & $1 \mathrm{I}$ & 0.89 & 0.27 & 0.97 \\
3 & $2 \mathrm{~V}$ & 0.80 & 0.31 & 1.00 \\
4 & $2 \mathrm{I}$ & 0.72 & 0.95 & 0.75 \\
5 & $3 \mathrm{~V}$ & 0.93 & 0.63 & 0.95 \\
6 & $3 \mathrm{I}$ & 0.93 & 1.00 & 0.67 \\
7 & $4 \mathrm{~V}$ & 0.72 & 0.57 & 0.06 \\
8 & $4 \mathrm{I}$ & 0.55 & 0.36 & 0.00 \\
9 & $5 \mathrm{~V}$ & 0.72 & 0.18 & 0.71 \\
10 & $5 \mathrm{I}$ & 0.86 & 0.35 & 0.70 \\
11 & $6 \mathrm{~V}$ & 0.00 & 0.04 & 0.55 \\
12 & $6 \mathrm{I}$ & 1.00 & 0.24 & 0.80 \\
13 & $7 \mathrm{~V}$ & 0.77 & 0.57 & 0.89 \\
14 & $7 \mathrm{I}$ & 0.91 & 0.57 & 0.86 \\
15 & $8 \mathrm{~V}$ & 0.66 & 0.28 & 1.00 \\
16 & $8 \mathrm{I}$ & 0.99 & 0.00 & 0.84 \\
\hline
\end{tabular}

Table 12 Experiment classification

\begin{tabular}{lrr}
\hline Number & Exp. & Total \\
\hline 6 & $3 \mathrm{I}$ & 4.59 \\
5 & $3 \mathrm{~V}$ & 4.58 \\
4 & $2 \mathrm{I}$ & 4.47 \\
10 & $5 \mathrm{I}$ & 4.44 \\
13 & $7 \mathrm{~V}$ & 4.34 \\
14 & $7 \mathrm{I}$ & 4.33 \\
12 & $6 \mathrm{I}$ & 4.19 \\
9 & $5 \mathrm{~V}$ & 4.11 \\
3 & $2 \mathrm{~V}$ & 3.91 \\
2 & $1 \mathrm{I}$ & 3.36 \\
16 & $8 \mathrm{I}$ & 3.33 \\
1 & $1 \mathrm{~V}$ & 3.24 \\
7 & $4 \mathrm{~V}$ & 2.94 \\
15 & $8 \mathrm{~V}$ & 2.85 \\
11 & $6 \mathrm{~V}$ & 2.56 \\
8 & $4 \mathrm{I}$ & 1.84 \\
\hline
\end{tabular}

encoded the mechanical results (Table 5) with an encoding "the larger the better" [20] (Eq. 8).

$x_{i j}=\frac{X_{i j}-\left(X_{j}\right)_{\min }}{\left(X_{j}\right)_{\max }-\left(X_{j}\right)_{\min }}$

The usefulness of the coding is to place every mechanical characterisation (Table 11) on the same scale of 0 to 1 , thus making mechanical characterisations comparable.

We can give a weight to the three mechanical performances. The final ranking depends heavily on this choice of weight. If we give equal weight to the three mechanical performances, it is to make the sum of the terms on the same line and then classify the amounts obtained (Table 12). We see (Table 12) that experiment 3 is the best compromise in terms of mechanical performance (see the conditions of manufacture (Table 13)).

First, it can be noted that the plate is stitched, which brings benefits in terms of shear strength and compressive strength (Eqs. 2 and 3). The resin, mould and curing temperatures are high. This finds no echo in the linear model proposed. One can see the impact of a more complete curing on the mechanical properties. The number of NCFs is four, which, as we have seen, produces better compressibility of the preform. The vacuum level reached is $1.4 \mathrm{mbar}$ which is not the best sealing obtained during testing.

The number of high-porous media is one, in agreement with Eq. 2. According to Eq. 2, using a single HPM to manufacture a composite gives improved compressive 
Table 13 Multi-objective optimised manufacture parameters

\begin{tabular}{lllcccccccc}
\hline Number & Exp. & Stitching & $\begin{array}{l}\text { Number } \\
\text { of NCF }\end{array}$ & $\begin{array}{l}\text { Temp. } \\
\text { injection }\left({ }^{\circ} \mathrm{C}\right)\end{array}$ & $\begin{array}{l}\text { Interaction } \\
\text { NCF, HPM }\end{array}$ & $\begin{array}{l}\text { mould } \\
\text { temp. }\left({ }^{\circ} \mathrm{C}\right)\end{array}$ & $\begin{array}{l}\text { Number } \\
\text { of HPM }\end{array}$ & $\begin{array}{l}\text { Cure temp. } \\
\left({ }^{\circ} \mathrm{C}\right)\end{array}$ & Plate side & $\begin{array}{l}\text { Vacuum pressure } \\
\text { level (mbar) }\end{array}$ \\
\hline 5 & $3 \mathrm{~V}$ & With & 4 & 80 & 1 & 120 & 1 & 180 & Vacuum & 1.4 \\
6 & $3 \mathrm{I}$ & With & 4 & 80 & 1 & 120 & 1 & 180 & Injection & 1.4 \\
\hline
\end{tabular}

strength. With four NCFs and a high-porous medium, Eq. 6 predicts a higher rate of fibre interaction. The injection-side manufactured composite also has a better mechanical compromise. This suggests that it is important to limit the distance between the injection point and any point of the manufactured part.

\section{Conclusions}

The mechanical and morphological properties of laminates infused with carbon NCF preforms, stitched or nonstitched, and epoxy RTM 6 are influenced by the process parameters of liquid resin infusion. The model predicts that the influence of parameters on mechanical properties could be, in the worst case, as high as 40-50\% of the minimal value (tensile, compression, ILSS) or $30 \%$ of an average value.

A greater distance relative to the entry points of the resin decreases tensile strength. Unsurprisingly, stitching improves ultimate compression strength and interlaminar shear strength. More surprisingly, however, a higher vacuum pressure improves interlaminar shear strength. Using only one high-porous medium improves ultimate compression strength.

The thickness sensitivity to the parameters can be also as high as $30 \%$. Thickness decreases with fabric number, highporous media compressibility and vacuum level (-1) reached. Fibre volume content is dependent on the same parameters as thickness but also decreases with preform (mould) temperature.

Fibre volume content decreases with stitching, with mould temperature and with the number of high-porous media. Fibre volume content increases with resin temperature during injection.

Porosity content increases with injection and cure temperature and with vacuum pressure $(+1)$. A multioptimisation analysis identified the most interesting manufacturing conditions.

The limitations of this study are mainly related to the asymmetry of the heating system used in the manufacturing process, which leads to temperature differences $\left(5{ }^{\circ} \mathrm{C}\right)$ that are higher than the more costly devices (autoclave, oven). Particular attention should be paid to conditions of convection on the upper side of the plate during curing, with a heating table to improve temperature accuracy.

\section{References}

1. Takeda F, Nishiyama S, Hayashi K and al., Research in the application of the VaRTM technique to the fabrication of primary aircraft composite structures. Mitsubishi Heavy Industries, Technical Review Vol. 42 (No. 5), 2005. http://www.mhi.co.jp/technology/ review/pdf/e425/e425220.pdf. Accessed 10 May 2012

2. Beckwith SW (2006) Resin infusion liquid molding vacuum infusion processing numerous other names. An alphabet soup of expanding technologies. SAMPE Journal 42(1):4

3. Teemer L, Okoli O, Liang Z (2006) The effect of processing parameters on the mechanical properties of components manufactured using the resin infusion between double flexible tooling process. SAMPE '06 Long Beach 51:9

4. Mattsson D, Joffe R, Varna J (2007) Methodology for characterization of internal structure parameters governing performance in NCF composites. Compos Part B: Eng 38(1):44-57

5. Lundström (2000) The permeability of non-crimp stitched fabrics. Compos Part A: Appl Sci Manuf 31(12):1345-1353

6. Timms, Mulchandani, Govignon Q and Bickerton S (2008) Identifying sources of variability in the mechanical performance of resin infused textile composites. The 9th international conference on textile composites (TexComp9), Newark, DE

7. Dransfield K, Baillie C, Mai YW (1994) Improving the delamination resistance of CFRP by stitching - a review. Compos Sci Technol 50(3):305-317

8. Govignon Q, Bickerton S, Morris J et al (2008) Full field monitoring of the resin flow and laminate properties during the resin infusion process. Compos Part A: Appl Sci Manuf 39:1412-1426

9. Olivier P, Cottu JP, Ferret B (1995) Effects of cure cycle pressure and voids on some mechanical properties of carbon/epoxy laminates. Composites 26(7):509-515

10. Ruiz, Achim EV et al (2006) Optimization of injection flow rate to minimize micro/macro-voids formation in resin transfer molded composites. Compos Sci Technol 66(3-4):475-486

11. Breard J, Saouab A, Bouquet G (2003) Numerical simulation of void formation in LCM. Compos Part A: Appl Sci Manuf 34 (6):517-523

12. Lawrence, Neacsu V, Advani S (2009) Modeling the impact of capillary pressure and air entrapment on fibre tow saturation during resin infusion in LCM. Compos Part A: Appl Sci Manuf 40 (8):1053-1064

13. Ledru Y, Bernhart G, Piquet R, Schmidt F, Michel L (2010) Coupled visco-mechanical and diffusion void growth modelling during composite curing. Compos Sci Technol 70(15):2139-2145 
14. Berthet F (2008) Calcul et expériences sur le profil du front de résine en infusion. Rev Compos Matér Avancés 18(3):375391

15. Sutherland LS, Shenoi RA, Lewis SM (1999) Size and scale effects in composites: II. Unidirectional laminates. Compos Sci Technol 59:221-233

16. Nakouzi S, Pancrace J, Schmidt F et al (2011) Simulations of an infrared composite curing process. Adv Eng Mater 13(7 and SI):604-608. doi:10.1002/adem.201000344

17. Yenilmez B, Senan M, Sozer EM (2008) Variation of part thickness and compaction pressure in vacuum infusion process. Compos Sci Technol 69(11-12):28
18. Donadon MV, Iannucci L, Falzon BG et al (2007) Intralaminar toughness characterisation of unbalanced hybrid plain weave laminates. Compos Part A: Appl Sci Manuf 38(6):1597-1611

19. Klunker F, Aranda S, Ziegmann G et al. (2008) Permeability and compaction models for non crimped fabrics to perform 3D filling simulations of vacuum assisted resin infusion. The 9th International Conference on Flow Processes In Composite Materials, Montréal (Québec), Canada

20. Chang SH, Hwang JR, Doong JL (2008) Optimization of the injection molding process of short glass fiber reinforced polycarbonate composites using grey relational analysis. J Mater Process Technol 97(1-3):186-193 